\title{
Optimum of interlayers in reconstructed soil with Yellow River sediment for restoring subsided coal mined land to farmland
}

\author{
Zhenqi $\mathrm{Hu}^{1}$, Xiaotong $\mathrm{Wang}^{2}$, Kevin $\mathrm{McSweeney}^{3}$, and Yong $\mathrm{Li}^{1}$ \\ ${ }^{1}$ China University of Mining and Technology - Beijing Campus \\ ${ }^{2}$ Peking University \\ ${ }^{3}$ University of Illinois at Urbana-Champaign
}

April 28, 2021

\begin{abstract}
Underground coal mining causes land subsidence, a large area of cultivated land is destroyed. The Yellow River interlayer filling reclamation technology is the powerful way to restore cultivated land. Understanding the mechanism of action of interlayers in reconstructed soil filled with Yellow River sediments is essential to achieving sustainable land management in the Yellow River regions. Column experiments and Field experiments were conducted to optimum of interlayers in reconstructed soil with Yellow River sediment for restoring subsided coal mined land. Our findings show that the inclusion of interlayers in the sediment reduced water leakage and moisture evaporation, and improved the water-holding capacity of the material in comparison to conventional reconstructed soil profile ( $\mathrm{Ck} 2)$. When the $30 \mathrm{~cm}$ thickness of interlayer, putting 2 interlayers in sediment (T6) was the optimal profile with the highest water-holding capacity. In comparison to CK2, the migration rate of wet front decreases by $32.16 \%$, the cumulative evaporation decreases by $16.29 \%$, the volumetric water content of filling layer ( $\left.\vartheta_{-} \mathrm{fl}\right)$ increases by $121.56 \%$, and the water-holding coefficient (CWR) increases by $59.47 \%$. It is also proved by field experiments. The wheat and maize yields of T6 improved $51.84 \%$ and $54.80 \%$, respectively, as compared with CK2, that closer to undisturbed farmland (CK1). This study provides a valuable framework for subsided land reclamation regarding the method of placing interlayers into Yellow River sediment for enhancing water retention and productivity.
\end{abstract}

Optimum of interlayers in reconstructed soil withYellow River sediment forrestoring subsided coal mined land to farmland

Zhenqi Hu 11Institute of Land Reclamation and Ecological Restoration, China University of Mining and Technology (Beijing), Beijing, China., Xiaotong Wang 22College of Urban and Environmental Sciences, Peking University, Beijing, China., Kevin McSweeney 33Department of Natural Resources and Environmental Sciences, University of Illinois at Urbana-Champaign, Urbana, USA., Yong $\mathbf{L i}^{\mathbf{1}}$

\section{Correspondence}

Zhenqi Hu, 345 Zonghe Building, D11 Xueyuan Road, Haidian District, Beijing, China.

E-mail: huzq1963@163.com;

Running Head: Restoring subsided coal mined land to farmland

\section{Acknowledgments}

This work was funded by the National Natural Science Foundation of China (No. 41771542). The authors would like to express appreciation to members of the research group at the China University of Mining and Technology for providing great help in terms of field operations. 


\section{Hosted file}

Main text.pdf available at https://authorea.com/users/410710/articles/519982-optimum-ofinterlayers-in-reconstructed-soil-with-yellow-river-sediment-for-restoring-subsidedcoal-mined-land-to-farmland

\section{Hosted file}

Tables.pdf available at https://authorea.com/users/410710/articles/519982-optimum-ofinterlayers-in-reconstructed-soil-with-yellow-river-sediment-for-restoring-subsidedcoal-mined-land-to-farmland

\section{Hosted file}

Figure legends.pdf available at https://authorea.com/users/410710/articles/519982-optimumof-interlayers-in-reconstructed-soil-with-yellow-river-sediment-for-restoring-subsidedcoal-mined-land-to-farmland

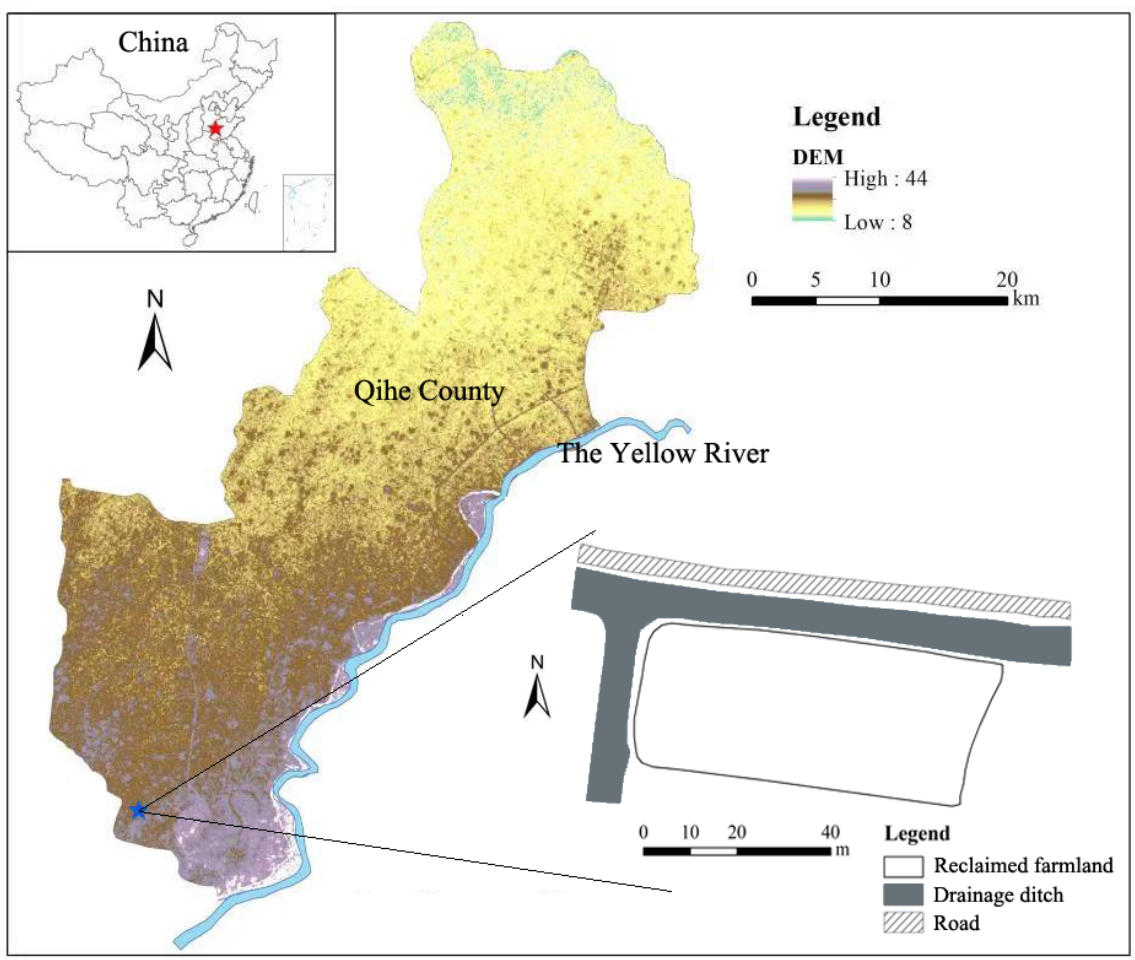



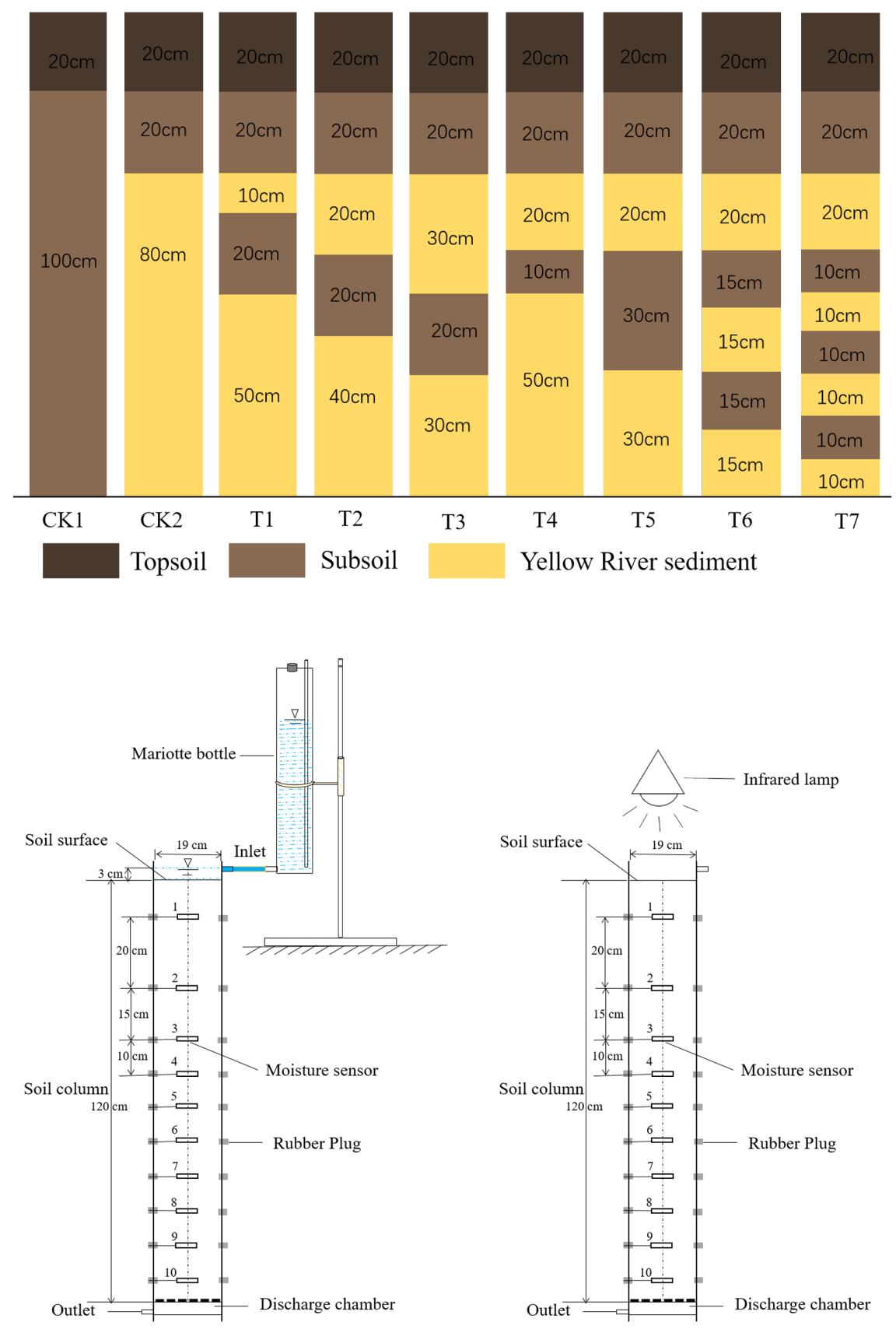

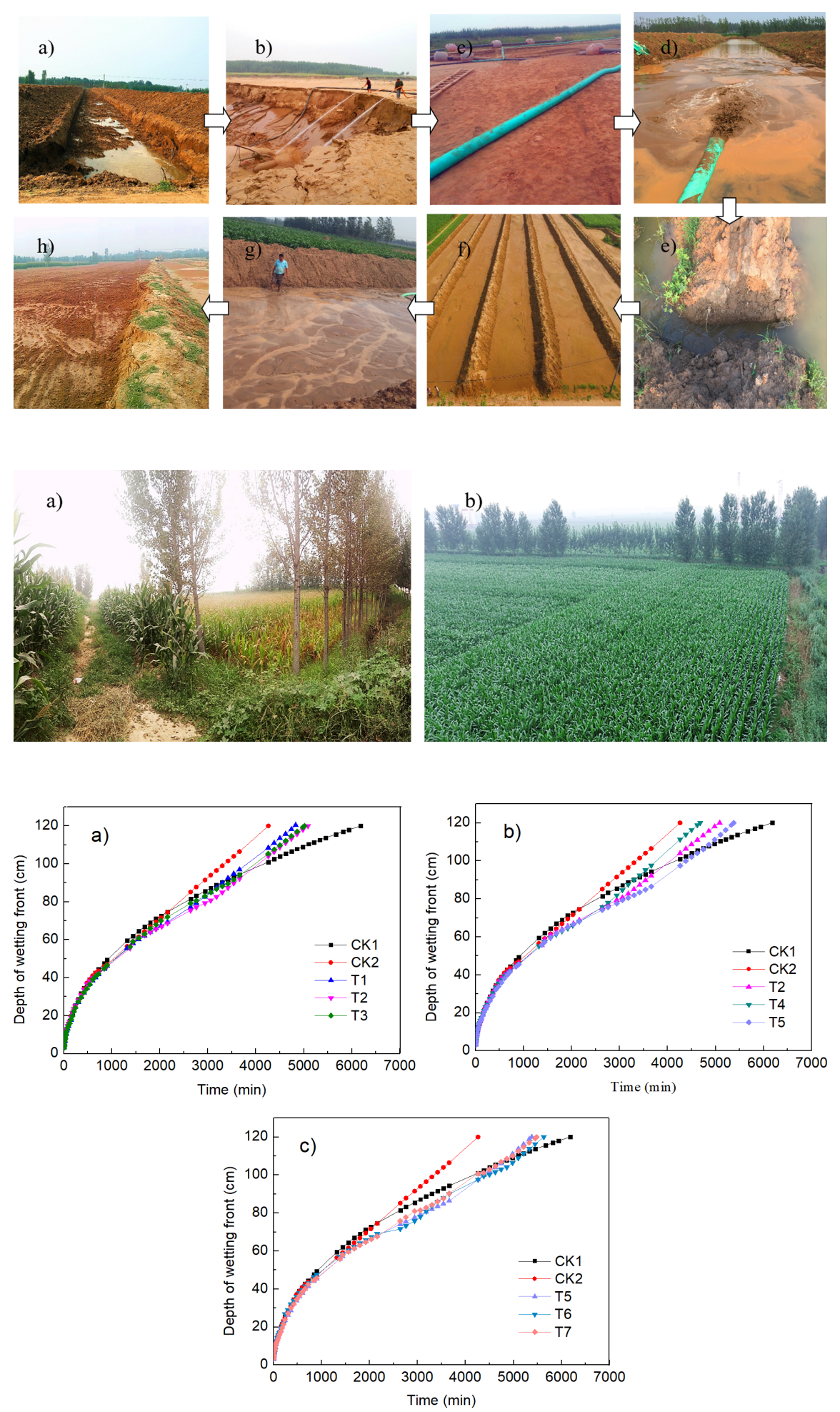

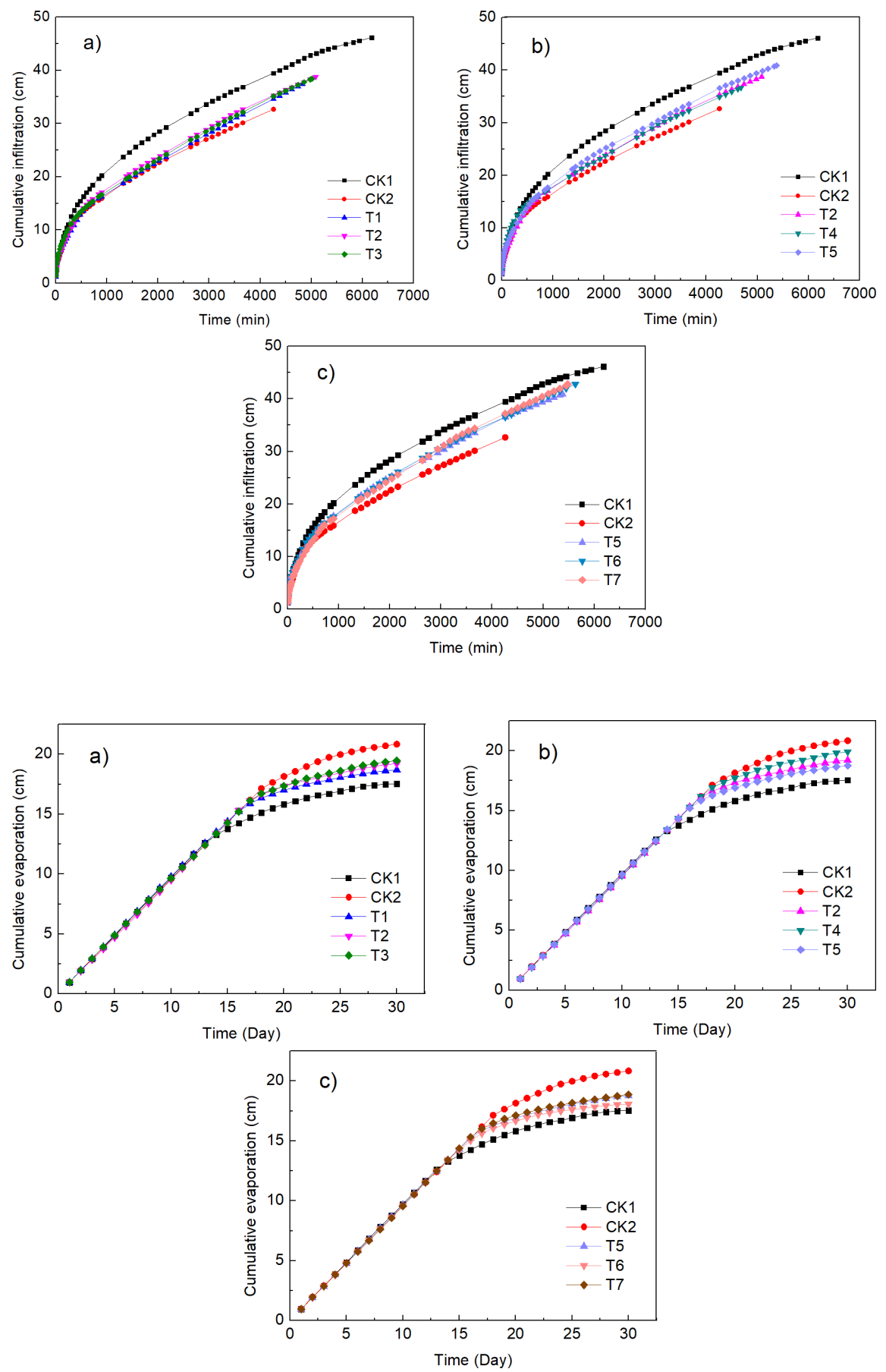

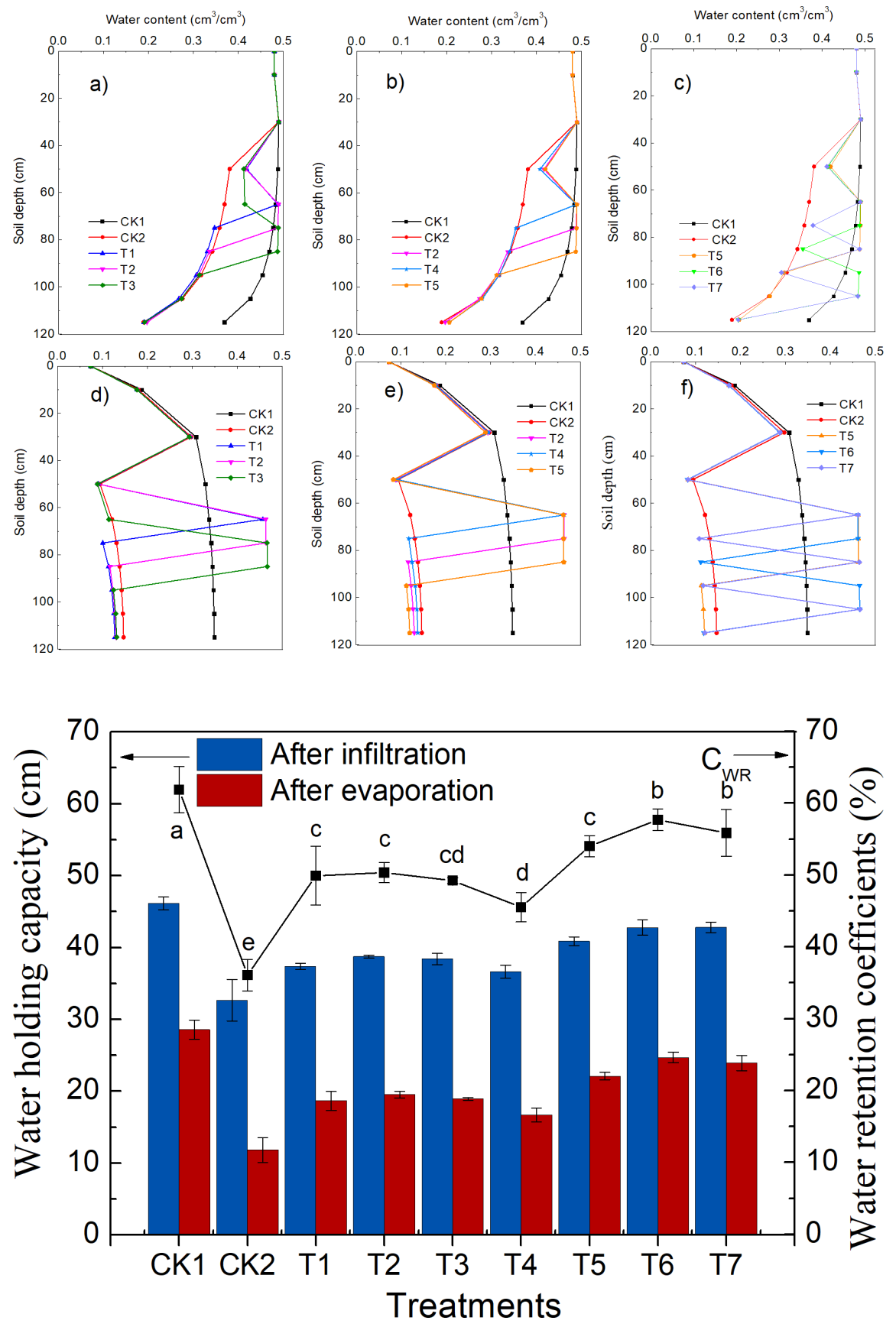

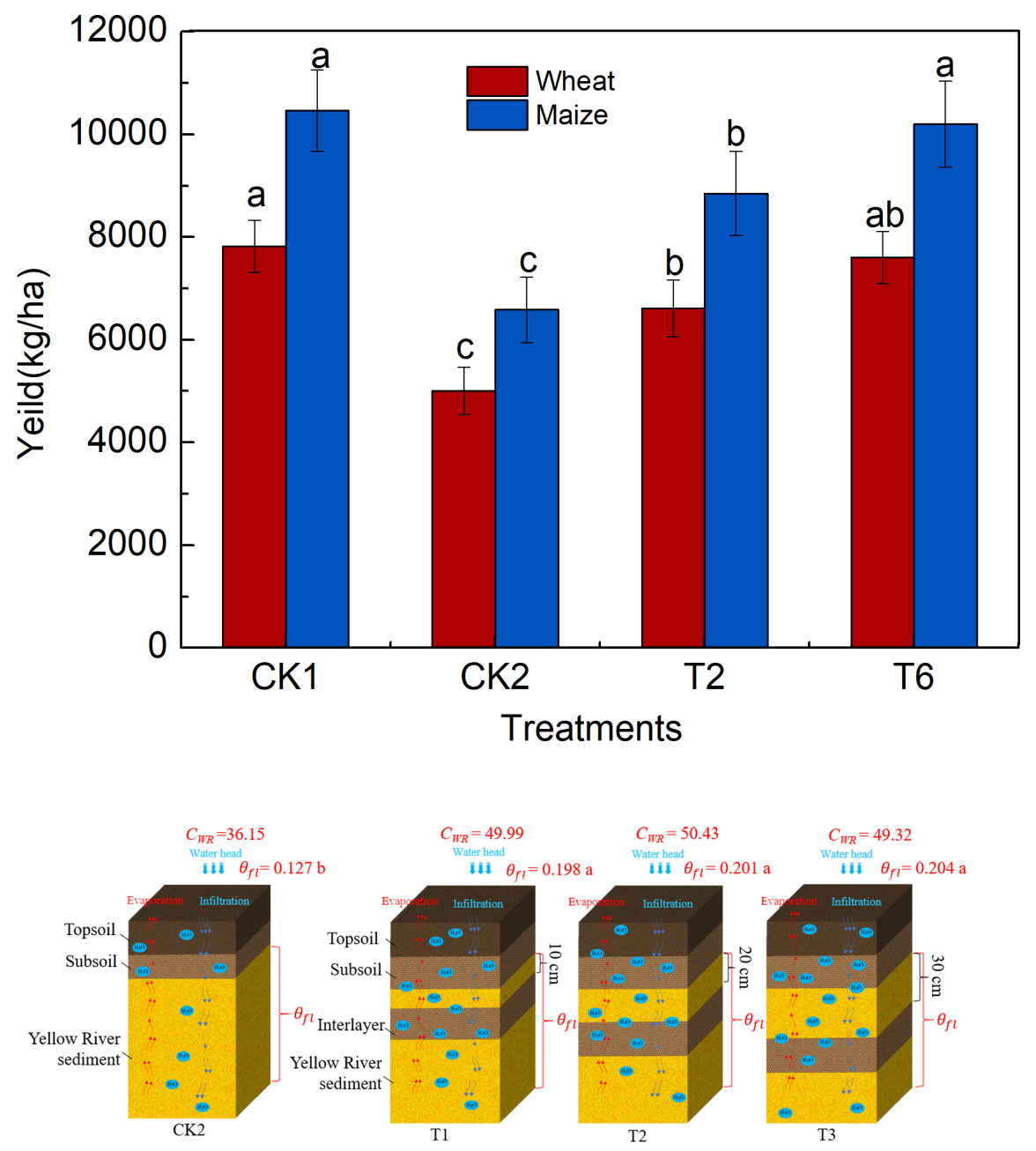

$\theta_{f l}:$ volumetric water content in filled layer $\left(\mathrm{cm}^{3} / \mathrm{cm}^{3}\right)$

$C_{W R}$ : the water retention coefficient (\%)

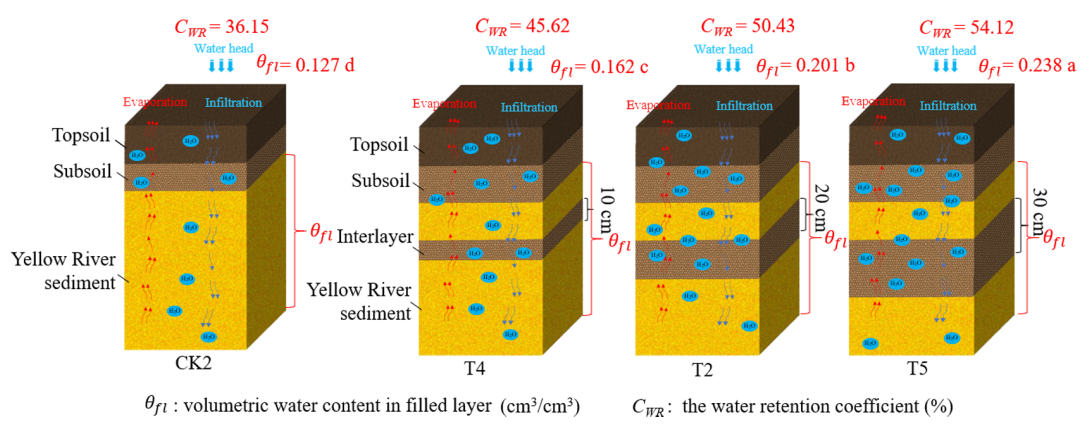




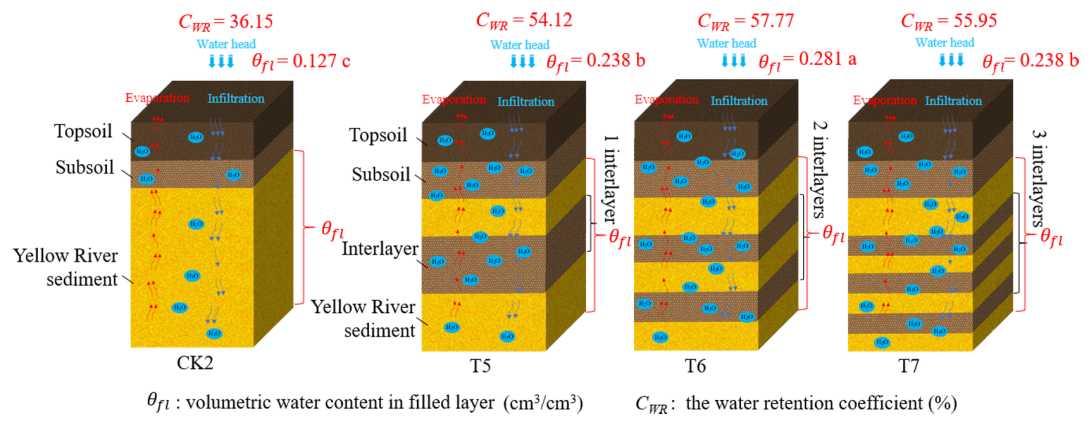

